\title{
Papillary mucinous cystadenocarcinoma: rare malignant tumor in minor salivary gland
}

\author{
Cistadenocarcinoma papilar mucinoso: tumor maligno raro em glândula salivar menor
}

\author{
Ronaldo Célio MARIANO' \\ Marina Reis OLIVEIRA ${ }^{2}$ \\ Amanda de Carvalho SILVA' \\ Lúcia de Carvalho Freire MARIANO² \\ Pablo Agustin VARGAS ${ }^{3}$ \\ Oslei Paes de ALMEIDA ${ }^{3}$
}

\begin{abstract}
Clinical case description of a papillary mucinous cystadenocarcinoma, extremely rare malignant tumor in the salivary gland and difficult to diagnose, in geriatric patient. Patient with 86 years old was referred for treatment with nodular lesion on the inner side of left lower lip extending to the bucal mucosa, without any clinical appearances of malignancy. The lesion was asymptomatic, had flabby consistency and slow growth. Despite the favorable clinical features, after surgical removal, was diagnosed as papillary mucinous papillary mucinous cystadenocarcinoma. Nonetheless, the cellular atypia found was considered to be mild and immunohistochemical evaluation the reaction to Ki-67 was low, indicating a low rate of proliferation of the tumor. Medical evaluation confirmed the absence of systemic disorders or distant metastases. Although it is a malignant lesion, due to low degree of proliferation of lesion and the careful follow-up carried out, there was a favorable evolution after conservative treatment in a follow-up period of 11 years and six months.
\end{abstract}

Indexing terms: Cystadenocarcinoma. Neoplasm. Salivary gland.

\section{RESUMO}

Descrição do caso clínico de um cistadenocarcinoma papilar mucinoso, tumor maligno extremamente raro em glândula salivar e de difícil diagnóstico, em um paciente geriátrico. Paciente com 86 anos foi encaminhado para tratamento com lesão nodular na parte interna do lábio inferior do lado esquerdo estendendo-se para a mucosa jugal sem qualquer aspecto clínico de malignidade. A lesão era assintomática, apresentava consistência flácida e crescimento lento. Apesar das características clínicas favoráveis, após a remoção cirúrgica, o diagnóstico foi de cistadenocarcinoma papilar mucinoso. Entretanto, a atipia celular encontrada foi considerada leve e a reação imunohistoquímica para - Ki67 baixa, indicando uma baixa taxa de proliferação do tumor. A avaliação médica confirmou a ausência de transtornos sistêmicos e de metástases a distância. Apesar de se tratar de uma lesão maligna, devido ao baixo grau de proliferação do tumor e o acompanhamento cuidadosos realizado houve uma evolução favorável após o tratamento conservador após um período de acompanhamento de 11 anos e 6 meses.

Termos de indexação: Cistadenocarcinoma. Neoplasias. Glândulas salivares.

\section{INTRODUCTION}

Malignant tumors of the salivary glands are rare, comprising from 1 to $6 \%$ of all head and neck tumors and the parotid is most commonly affected, accounting for $70 \%$ of the lesions ${ }^{1}$. Papillary cystadenocarcinoma, in turn, comprises an extremely rare lesion, accounting for $0.5 \%$ of all epithelial lesions affecting the salivary glands ${ }^{2}$ and according to the second largest survey on cystadenocarcinomas described in the literature, the highest prevalence is also observed in the major salivary glands ${ }^{3}$.

There are between 450 and 750 minor salivary glands distributed in the head and neck area ${ }^{4}$ and neoplasms affecting these structures are usually malignant. These tumors have enormous diversity in their morphology and appearance ${ }^{5}$. Such characteristics associated with oncologists' scarce clinical experience in this type of

\footnotetext{
${ }^{1}$ Universidade Federal de Alfenas, Faculdade de Odontologia, Departamento de Clínica e Cirurgia. Rua Gabriel Monteiro da Silva, 700, Prédio G, Centro, 37130-000, Alfenas, Minas Gerais, Brasil. Correspondência para / Correspondence to: RC MARIANO. E-mail: <ronaldocmariano@gmail.com>

${ }^{2}$ Universidade Estadual Paulista Júlio de Mesquita Filho, Faculdade de Odontologia, Departamento de Diagnóstico e Cirurgia. Araraquara, SP, Brasil.

${ }^{3}$ Universidade Estadual de Campinas, Faculdade de Odontologia, Departamento de Diagnóstico Oral. Piracicaba, SP, Brasil.
} 
injury complicate diagnosis and treatment, hindering the prognosis and becoming a real challenge for clinicians and pathologists'.

Minor salivary gland tumors are distributed in the upper aerodigestive tract, palate, paranasal sinuses, nasal cavity, tongue, gums, pharynx, larynx and trachea ${ }^{6}$ and comprise several subtypes ${ }^{5}$. However, most of these lesions are intraoral and appear as painless swelling. The presence of painful symptoms is more common in cases of lesions with malignant characteristic, but asymptomatic malignant tumors of minor salivary glands are not uncommon either ${ }^{7}$.

Many malignant tumors of salivary glands are characterized by abundant secretion of mucin. Mucoepidermoid carcinoma, salivary duct carcinoma, and cystadenocarcinoma are part of this group of mucin-producing tumors, among others. Mucus is the predominant histological component of these lesions, and the ratio between extracellular mucin and epithelial portion is variable. Therefore, the confluence of characteristics between tumors associated with the rarity of the lesions make it difficult to perform an accurate diagnosis ${ }^{8}$. Among these lesions, cystadenocarcinoma stands out due to its rarity in the salivary gland with only a large series of 57 cases described in the literature ${ }^{3}$. Thus, it is pertinent to the description of this clinical case.

\section{CASE REPORT}

Patient, 86 years old, male, with leukoderma, was referred for treatment with elevation on the inner side of left lower lip extending to the bucal mucosa. The lesion was asymptomatic and had flabby consistency on palpation and, according to the patient, slow growth has been observed for one year. Clinical evaluation identified a nodular lesion of sessile base, well-defined, covered by normal-colored mucosa, but it had a point of mucosal fluid drainage (Figure 1).

Given the characteristics of the lesion without any clinical appearances of malignancy, excisional biopsy of the lesion was proposed under local anesthesia. For such, an incision was performed delimiting the nodule preceded by dissection and complete removal of the lesion (Figure 2). Despite the favorable clinical features, it was diagnosed papillary mucinous cystadenocarcinoma of low-grade malignancy. Microscopically, the lesion was described as having multiple cystic spaces surrounded by the papillary projections of the dysplastic epithelium (Figure 3).
Nonetheless, the cellular atypia found was considered to be mild. Immunohistochemical evaluation of the lesion was also performed, showing positive reaction to the markers CK7, CK18, CEA and negative reaction to CK14, CK20, TTF-1, and PSA. Furthermore, the reaction to $\mathrm{Ki}-67$ was low, indicating a low rate of proliferation of the tumor. A strong staining for mucin was observed, revealing the key component of the tumor (Figure 4).

At the postoperative period of 15 days, for suture removal, it was observed satisfactory repair. Medical evaluation confirmed the absence of systemic disorders or distant metastases. Clinical follow-up was carried out throughout 11 years and 6 months with periodic returns (Figures 5). During this period no recurrence or metastasis was observed.

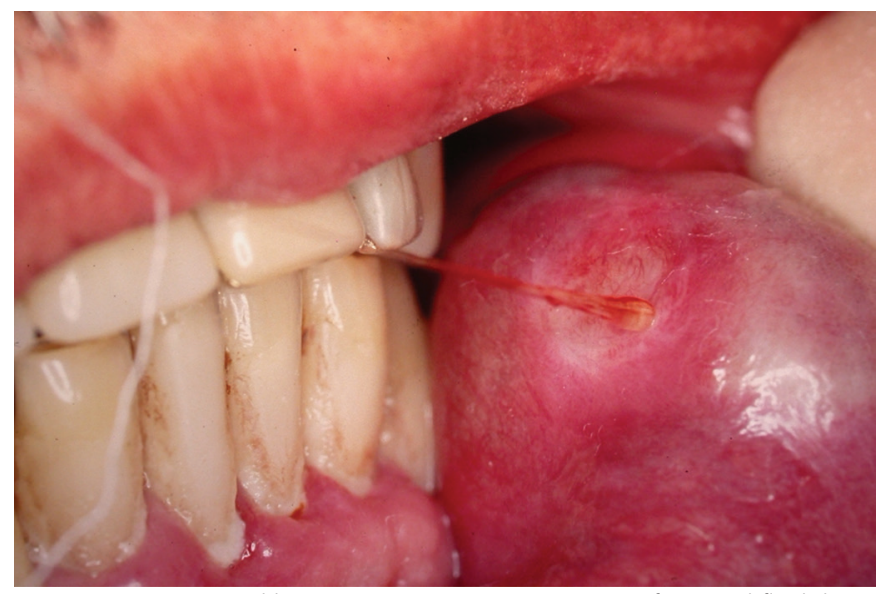

Figure 1. Injury covered by intact mucosa presenting point of mucosal fluid drainage.

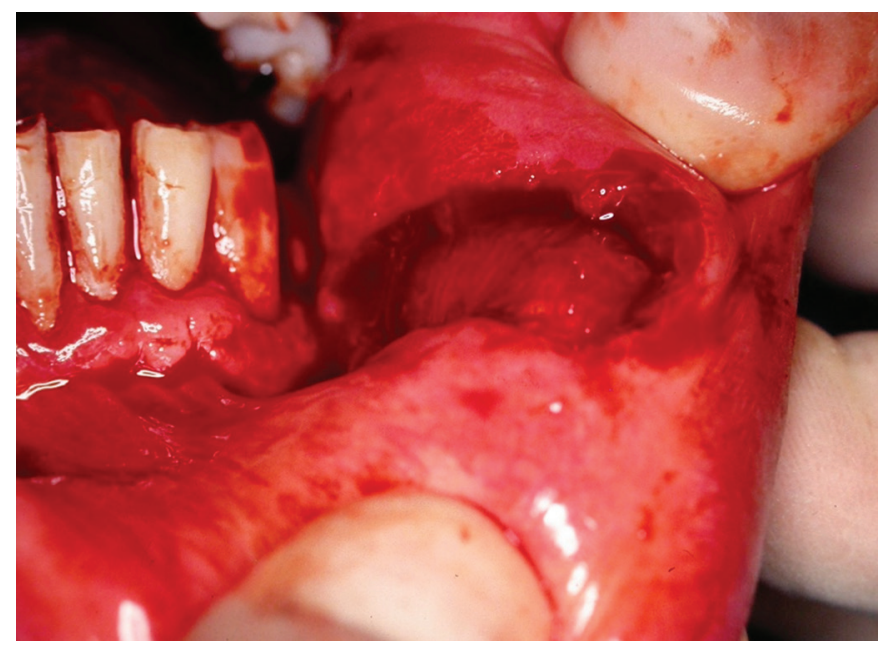

Figure 2. Surgical wound after complete removal of the lesion. 


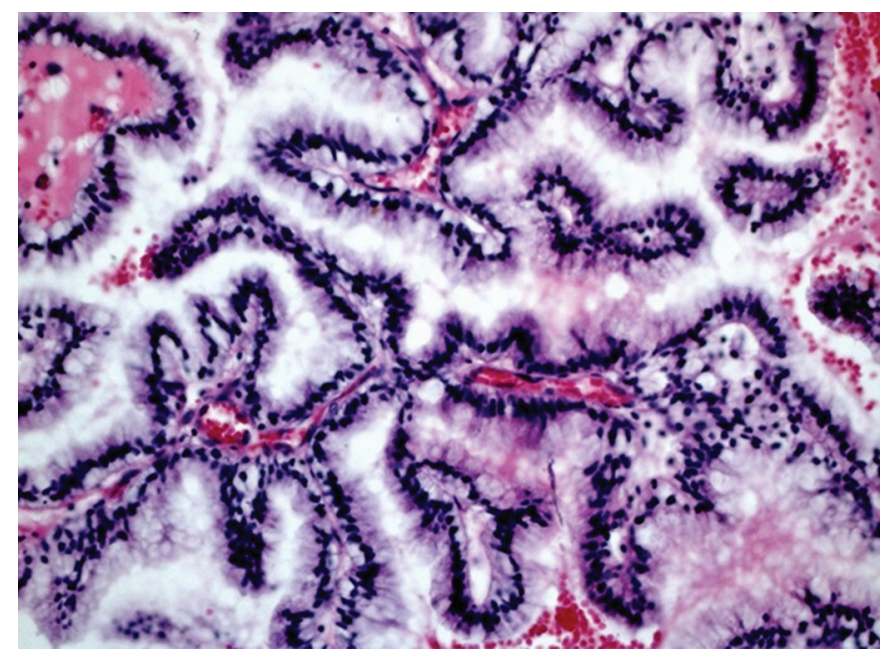

Figure 3. Surgical wound after complete removal of the lesion.

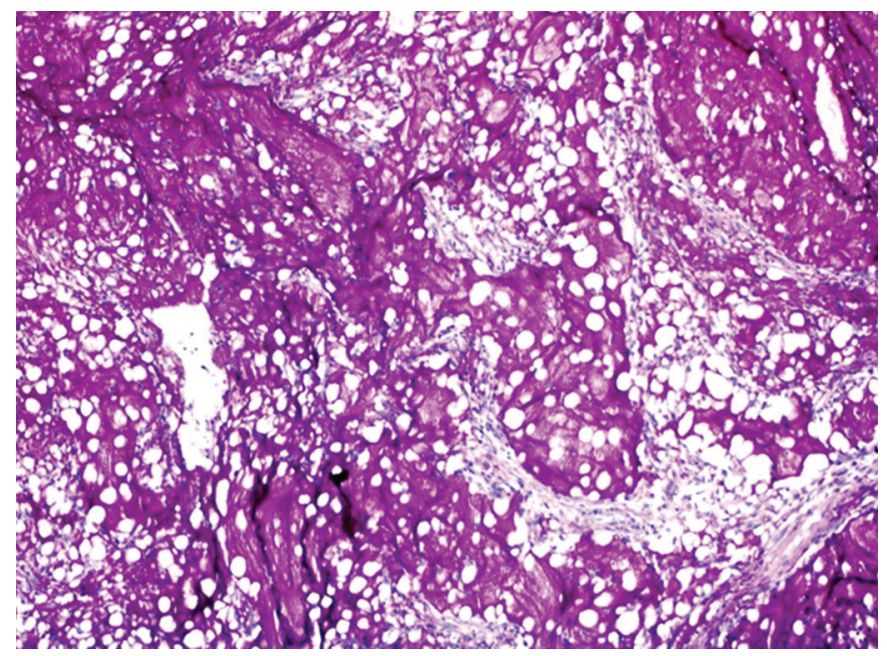

Figure 4. Strong staining by mucin showing the key component of the tumor.

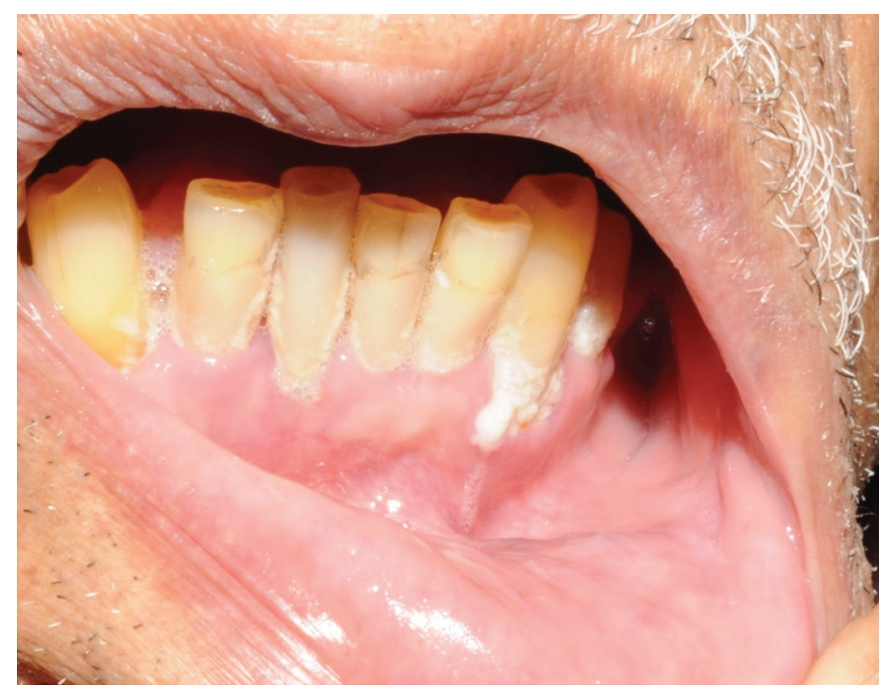

Figure 5. Sound appearance of the operated site in the follow-up of 11 years and 6 months.

\section{DISCUSSION}

Clinical characteristic of tumors of minor salivary glands appears to be quite variable. Most of the lesions are asymptomatic or with obvious symptoms for a short period in relation to the time they stay in the oral cavity ${ }^{7}$. In this clinical case, there was no history of painful symptoms, although the lesion had already been observed by the patient about 1 year ago.

A conduct widely used in the treatment of salivary gland tumors is the $4 \mathrm{~cm}$ rule ${ }^{9}$. According to Speight \& Barrett ${ }^{1}$, tumors smaller than $4 \mathrm{~cm}$ have higher survival rates and lower incidence of regional or distant metastases and in those cases, radiation therapy is not indicated. These reports in the literature could explain, in part, the absence of metastases and the high survival rate of the patient of this clinical case due to the small size of the tumor.

According to Chandana \& Conley ${ }^{6}$, tumors of minor salivary glands are most commonly presented as an asymptomatic volumetric increase of the ulcerated/ non-ulcerated mucosa. In most cases, papillary cystadenocarcinoma is asymptomatic and has slow growth $^{10-11}$. The concerned clinical case was a painless nodule of sessile base, covered with normal and intact mucosa. In contrast, the tumor location in a minor salivary gland on the inner side of the lower lip may be considered atypical compared with the findings of Foss et al. ${ }^{3}$, where $65 \%$ of cystadenocarcinomas were located in the major salivary glands, preferably in the parotid. In addition, most tumors of the minor salivary glands located in the lip affect the upper lip, and lower lip lesions in most cases correspond to simple mucocele ${ }^{1}$. The lesion site (lower lip) in this case report complies with the findings of Foss et al. ${ }^{3}$, who observed that most cystadenocarcinomas afflicting minor salivary glands (35\%), affected the lips, followed by buccal mucosa, palate and tongue.

Papillary mucinous cystadenocarcinoma can be histologically described by the presence of large cystic spaces filled with mucus surrounded by exophytic papillary structures ${ }^{3}$. However, the presence of mucus and papillary projections is relatively common in lesions of salivary gland origin, which complicates the diagnosis ${ }^{12}$. Moreover, cystadenocarcinoma is generally well-defined and papillary or cribriform projections are present in $75 \%$ of cases. These projections are lined by small cubic cells, large cubic cells and columnar cells in $60 \%, 16 \%$ and $12 \%$ of cases, respectively, and a mixture of these cell types $(12 \%)$ may still be observed ${ }^{3}$. Pleomorphism and atypical mitoses are 
uncommon, but they have been reported in some cases ${ }^{11}$.

Therefore, this lesion is considered by WHO and several authors as of low-grade malignancy ${ }^{13}$. In this clinical case, papillary projections and cystic spaces were quite evident, resulting in the diagnosis of papillary mucinous cystadenocarcinoma.

In addition to the assessment of the slices by staining with hematoxylin and eosin, which is still considered by some authors as the gold standard for the diagnosis of salivary gland, immunohistochemistry was also performed. According to Aloudah et al. ${ }^{11}$, immunohistochemistry is not very useful for the differential diagnosis of salivary gland neoplasms and there is still no cystadenocarcinomaspecific antibody, however due to the rarity of the lesion, we chose to use various antibodies. However, there was low positivity to Ki-67, which means the tumor has a low proliferation rate and thus a low degree of malignancy ${ }^{10}$.

Regarding the form of treatment, according to the guidelines of the National Comprehensive Cancer Network (NCCN), the first-line treatment for carcinoma of major and minor salivary glands is surgical excision ${ }^{14}$ which can be associated or not with radiation therapy ${ }^{5}$. In the case of low-grade cystadenocarcinoma, because of its indolent behavior and low malignant potential, local but complete excision appears to be sufficient ${ }^{3}$.

As for survival, Kruse et al. ${ }^{4}$, reported excellent healing rates when complete resection of the tumor is achieved with infrequent metastases. Regarding cystadenocarcinoma, according to a review of 57 cases performed by the Institute of Pathology of the Armed Forces (AFIP), most patients showed survival during a follow-up period of 59 months $^{3}$. In this case report, an increased survival was observed, with more than 11 years of followup after total excision of the lesion, which was carried out without safety margins due to benign clinical appearance of the lesion preoperatively. After the histopathological diagnosis of a malignant lesion, the patient underwent periodic medical/dental follow-up and no recurrence or metastasis was seen despite the conservative treatment performed.

The incidence and mortality rates of salivary gland cancers vary per race and sex, and according to Swanson \& Burns ${ }^{15}$, the average annual incidence of the disease for white males is 1.2 in every 100,000 inhabitants, while for black males is 1.0 in every 100,000 inhabitants. As for females, the incidence is 0.7 in every 100,000 inhabitants in both races, and despite the higher prevalence in men, the highest survival rates were observed in women. In the case of papillary mucinous cystadenocarcinoma, the highest prevalence occurs in adults, with a mean age of 58.8 years old, showing a peak incidence in the eighth decade of life and with no difference in disease onset between the sexes ${ }^{3}$. The patient in this case is an 86-yearold white male.

In this context, follow-up of patients who had salivary gland tumors is essential and aims at early recognizing relapses and identifying complications arising from the treatment ${ }^{8}$. Despite the cystadenocarcinoma described in this paper has a low degree of malignancy, the literature occasionally reports cases of recurrence (7.7\%) and regional metastases (10\%), therefore followup of this kind of injury should not be considered less important ${ }^{2}$. The periodic returns are important especially in the first three years, since $70 \%$ of recurrences of minor salivary gland tumors occur in this period ${ }^{4}$. Follow-up visits should be scheduled periodically, according to the risk of disease recurrence and should be performed by head and neck surgeons or oncologists and dentists ${ }^{14}$. In this clinical case, the medical/dental follow-up over 10 years revealed no recurrences, metastases or other complications and, according to Gallego et al. ${ }^{12}$, in cases of low-grade cystadenocarcinoma, which is the lesion described in this case, annual reviews for a 5-year period seem to be sufficient.

\section{CONCLUSION}

Although it is a malignant lesion, due to low degree of proliferation of lesion and the careful followup carried out, there was a favorable evolution after conservative treatment in a follow-up period of 11 years and six months.

\section{ACKNOWLEDGEMENTS}

We thank the Clinic \& Surgery Department, Alfenas Dental School, Federal University of Alfenas UNIFAL-MG, Minas Gerais, Brazil, and funding agencies CAPES, FAPEMIG and CNPQ.

\section{Collaborators}

RC MARIANO was responsible surgical procedure, follow-up of the patient and the documentation of the clinical case. MR OLIVEIRA literature review, writing and submission of the manuscript. ACS LEOCÁDIO critical 
review of the writing of the manuscript and of the English version. LCF MARIANO assist in the surgical procedure, of the documentation of the clinical case and assisted in the preparation of the manuscript. PA VARGAS and OP

\section{REFERENCES}

1. Speight PM, Barretti AW. Salivary gland tumours. Oral Dis. 2002;8(5):229-40.

2. Agarwal S, Das P, Singh MK, Sharma A, Karak AK. Papillary cystadenocarcinomas of salivary glands with oncocytic epithelial lining: report of 2 cases. Int J Surg Pathol. 2008;16(3):341-4. doi: $10.1177 / 1066896907309580$

3. Foss RD, Ellis GL, Auclair PL. Salivary gland cystadenocarcinomas: a clinicopathologic study of 57 cases. Am J Surg Pathol. 1996;20(12):1440-47.

4. Kruse ALD, Gratz KW, Obwegeser JA, Lubbers HT. Malignant minor salivary tumors: a retrospective study of 27 cases. Oral Maxillofac Surg. 2010;14(4):203-9. doi: 10.1007/s10006-0100217-x

5. Loh KS, Barker E, Bruch G, Sullivan B, Brown DH, Goldstein $D P$, et al. Prognostic factors in malignancy of the minor salivary glands. Head Neck. 2009;31(1):58-63. doi: 10.1002/hed.20924

6. Chandana SR, Conley BA. Salivary gland cancers: currents treatments, molecular characteristics and new therapies. Expert Rev Anticancer Ther. 2008;8(4):645-52. doi: 10.1586/14737140.8.4.645

7. Copelli C, Bianch B, Ferrari S, Ferri A, Sesenna E. Malignant tumors of intraoral minor salivary glands. Oral Oncol. 2008;44(7):658-63. doi:10.1016/j.oraloncology.2007.08.018

8. Yakirevich E, Sabo E, Klorin G, Alos L, Cardesa A, Ellis GL, et al. Primary mucin-producing tumours of the salivary glands: a clinicopathological and morphometric study. Histopathology. 2010;57(3):395-409. doi: 10.1111/j.1365-2559.2010.03639.x
ALMEIDA realization of the histopathological diagnosis and support in the documentation and follow-up of the clinical case.

9. Speight PM, Barretti AW. Prognostic factors in malignant tumours of the salivary glands. Br J Oral Maxillofac Surg. 2009;47(8):58793. doi: 10.1016/j.bjoms.2009.03.017

10. Cavalcante RB, Miguel MCC, Carvalho ACS, Nogueira RLM, Souza LB. Papillary cistadenocarcinoma: Report of a case of high-grade histopathologic malignancy. Auris Nasus Larinx. 2007;34(2):259-62. doi:10.1016/j.anl.2006.07.010

11. Aloudah NM, Raddaoui E, Aldhahri S, Al-Abbadi MA. Lowgrade papillary cystadenocarcinoma of the parotid gland: presentation of a case with cytological, histopathological and immunohistochemical features and pertinent review. Diagn Citopathol. 2008;37(2):128-31. doi: 10.1002/dc.20971

12. Gallego L, Junquera L, Fresno MF, Vicente JC. Papillary cystadenoma and cystadenocarcinoma of salivary glands; two unusual entities. Med Oral Patol Oral Cir Bucal. 2008;13(7):4603.

13. Nakagawa T, Hattori K, Iwata N, Tsujimura T. Papillary cystadenocarcinoma arising from minor salivary glands in the anterior portion of the tongue: a case report. Auris Nasus Larynx. 2002;29(1):87-90. doi: 10.1016/S0385-8146(01)00121-3

14. Guzzo M, Locati LD, Prott FJ, Gatta G, McGurk M, Licitra L. Major and minor salivary gland tumors. Crit Rev in Oncol Hematol. 2010;74(2):134-48. doi: 10.1016/j.critrevonc.2009.10.004

15. Swanson GM, Burns PB. Cancers of the salivary gland: workplace risks among women and men. Ann Epidemiol. 1997;7(6):36974. doi: 10.1016/S1047-2797(97)00041-0

Received on: 24/2/2016

Final version resubmitted on:14/3/2016

Approved on: 13/4/2016 